and luck in the undetermined willing of the good will. Dickenson herself claims that a modified Nagelian Kantianism is the best approach to issues of moral luck in a chapter in which she finds problems of moral luck in consequentialism, whether it is based on actual or probable consequences.

A chapter is devoted to each of four practical issues.

The political questions discussed are those of secrecy and nuclear deterrence, and Dickenson argues against both. The first medical ethical issue covered is that of the allocation of scarce health care resources. Here Dickenson suggests that a lottery is required in allocation, except where the autonomy of nurses prevents their time being treated in the same way as other resources or where dependants are involved. Dickenson rejects the 'fair-innings' principle on the ground that there is no non-arbitrary view on what counts as a fair innings. A revamped argument from fairness, however, which centred purely on the relative lengths of life of candidates for treatment would not be vulnerable to this objection.

The second medical question discussed is that of informed consent. Here Dickenson runs the plausible line that a non-negligent doctor cannot be held responsible for a treatment's turning out badly if she had obtained informed consent from the patient beforehand.

A short review such as this cannot do justice to the richness and complexity of Dickenson's arguments. These issues - both theoretical and practical - are difficult, and she has perforce written a difficult book which will demand some knowledge of the literature in its readers.

ROGER CRISP St Anne's College, Oxford.

\section{Doctors, patients and the law}

\author{
Edited by Clare Dyer, Oxford, \\ Blackwell Scientific Publications, \\ 1992, 216 pages, $£ 15.99$
}

The last ten years have seen significant development in the burgeoning field of medical law. Such growth has been unrestrained by the traditional boundary of medical malpractice and has extended into laws regulating such activities as human fertility and patient access to records. This book is a timely summary of some of the more important issues arising in medical law.

Ms Dyer has assembled an impressive array of experts to contribute to Doctors, Patients and the Law. The book itself commemorates the centenary of the Medical Protection Society. The authors manage to outline the relevant issues in a way which is not only scholarly and lucid, but also interesting.

In the first chapter, Michael Jones examines the field of medical negligence and establishes the pattern for the rest of the book by using case law to focus on problems which may arise in everyday medical practice. Chapter two (written by Robert Lee) examines the areas of confidentiality and patient access to medical records. Chapters three and four examine consent to treatment by a capable patient (written by Ian Kennedy) and an incapable patient (written by Larry Gostin). In chapter five Sheila McClean examines the area of reproductive technology and includes in the discussion an interesting section on the effect that the various pieces of legislation have on maternal and fetal rights. Alexander McCall Smith tackles the difficult area of euthanasia in chapter six and J K Mason examines the law relating to organ transplants in chapter seven. Chapter eight (by Ian Dodds-Smith) examines rules regulating clinical research. Chapter nine (by Michael Spencer) looks at product liability. The last two chapters focus on the accountability of doctors (Roy Palmer) and employment rights (Brian Raymond).

The book is not simply a dry account of what the law is. The authors are quick to point out problems with existing law and to suggest new solutions. The book is remarkably up to date and references abound. It is a first-class source book.

The work has a couple of minor deficiencies. On occasion there are contradictions in the work (compare the differing definitions of competency offered on pages 58 and 76). The chapter on accountability and discipline, while being a good summary of the issues, suffers from a lack of footnotes referring to sections of the relevant acts. Finally, I believe the book would have benefited from an introductory chapter which explained in broad terms the contents and principal arguments of the authors. It would have been interesting to see a chapter on the NHS reforms and their effect on the delivery of medical practice (though, admittedly, some of these issues are explored tangentially in other chapters). Similarly, a chapter on legal responses to the AIDS problem might have been interesting

Overall, this book provides a fertile source of information on the myriad legal regulations affecting medical practice.

\section{J A DEVEREUX Keble College, Oxford. \\ Ethics in nursing - third edition}

Martin Benjamin and Joy Curtis, New York, Oxford University Press, 1992, 248 pages, $£ 15.00 \mathrm{pb}$

This volume is a valuable further addition to the health care ethics literature. Were it not for the American setting and language it would be $\mathbb{\Phi}$ possible to recommend it wholeheartedly. As it stands, if readers afo equipped with a willingness to exe cise some mental agility in recognisin the many parallels within their ow country then they will be richiy rewarded with some treasures in vivid case-studies and careful analysis.

The first two chapters introduce the $\stackrel{\mathbb{Q}}{\varrho}$ reader to ethical analysis and ethical $\overrightarrow{\hat{0}}$ frameworks. These are both lucid and 3 accessible. The impression is of a $\bar{P}$ well-grounded text for the novice and a useful though not wholly predictable review for the more experienced. Subsequent chapters centre upon ethical issues between nurses and 3 clients, nurse-physician relationships and dilemmas among nurses. In these the reader's imagination is captured with thoughtfully selected scenarios which are then subjected to rigorous $D$ analysis. The familiar issues of confi- 을 dentiality, deception, autonomy and $\mathrm{N}$ respect for persons are given due $\Omega$ weight. This interpersonal focus is $N$ replaced in the final two chapters by a N concern with broader questions of $\omega$ firstly institutional and public policy and secondly macroallocation of health care resources and justice. This last chapter constitutes the main new material for this third edition and con- $\square$ siderably strengthens the volume by immersing the discussion of health care ethics in collective concerns $\frac{\vec{D}}{\sigma}$ which are assuming ever greater $\varrho$ urgency in the latter part of the twentieth century. 